\title{
Customer Preferences for Online, Social Media, and Mobile Innovations in the Hospitality Industry
}

Cornell Hospitality Quarterly 53(3) $183-186$

(C) The Author(s) 2012

Reprints and permission:

sagepub.com/journalsPermissions.nav DOI: $10.1177 / 193896551244516$

htup://cqx.sagepub.com QSAGE

\author{
Rohit Verma', Debra Stock², and Laura McCarthy ${ }^{3}$
}

\begin{abstract}
The study discussed here summarizes the internet search preferences and mobile device use of 2,830 recent travelers. With regard to gathering information for a hotel stay, business travelers most often follow their company's recommendation for a hotel, although many of them use search engines or online travel agents to learn more about available hotels. In contrast, recommendations of friends and colleagues are most important to leisure travelers, followed by travel-related websites, search engines, and OTAs. Once the information is gathered, however, travelers of all kinds turn more to such sources as the brand website, OTAs, and TripAdvisor. Late in the decision process, the respondents tended to land on the brand websites or go to an OTA, where they can book their room.
\end{abstract}

\section{Keywords \\ Traveler preferences, social media}

With the encouragement of our advisory board, the Center for Hospitality Research (CHR) has for the past four years been investigating the impact of social media on the hospitality industry, including issues relating to marketing and distribution both in North America and internationally. In addition to research studies, we have organized two international Industry Roundtables, one in Singapore early in 2010 and the other in 2012, in Mumbai, India (see Verma and Smith, 2010). In these roundtables, we learned that participants believe that the hospitality operators are caught between their effort to meet the standards of international rating organizations and the need to respond to comments on social media websites. While recognizing the complexities and ambiguities surrounding social media ratings, the roundtable participants concluded that the most powerful promotional tool is word of mouth from a friend, and social media are an extension of this human network.

Acknowledging the ambiguities and anxiety surrounding the above issues, the CHR commissioned a research project to explore consumers' use of technology for search and purchase activities, including the effects of user comments on all electronic media. We also explored the evolving customer preferences for hospitality-related mobile apps.

After reviewing past research related to how customers search for and choose hotels online (see Bodenlos et al. 2010); the relationships between customers' demographics and their travel behavior; the similarities and differences between business and leisure travelers; and the relationship between travel preferences and individuals' willingness to adopt new technologies (see Verma et al. 2007), we conducted in-depth interviews with industry and academic experts to further expand the ideas identified during the literature review. We developed and sent a survey to a balanced sample of 4,000 business and leisure hotel customers within the United States and received a total of 2,830 useable responses almost evenly divided between men and women, and well balanced geographically and demographically (for more detail, see: McCarthy et al., 2010).

\section{Search Patterns of Business and Leisure Travelers}

We found that the top factor in hotel choice for business travelers is the recommendation of the company or organization, cited by 40 percent of the business travelers in our study. To a lesser extent, business travelers did consult search engines and meta-search sites to learn about potential hotels.

In stark contrast, the number one source of hotel information for leisure travelers is the recommendations of

'Cornell University School of Hotel Administration, Ithaca, NY, USA

${ }^{2}$ Expedia

${ }^{3}$ TIG Global

Corresponding Author:

Rohit Verma, Cornell University School of Hotel Administration, Statler Hall, Ithaca, NY 14853, USA

Email: rv54@cornell.edu 


\section{Exhibit 1:}

Sites consulted at three purchase stages.

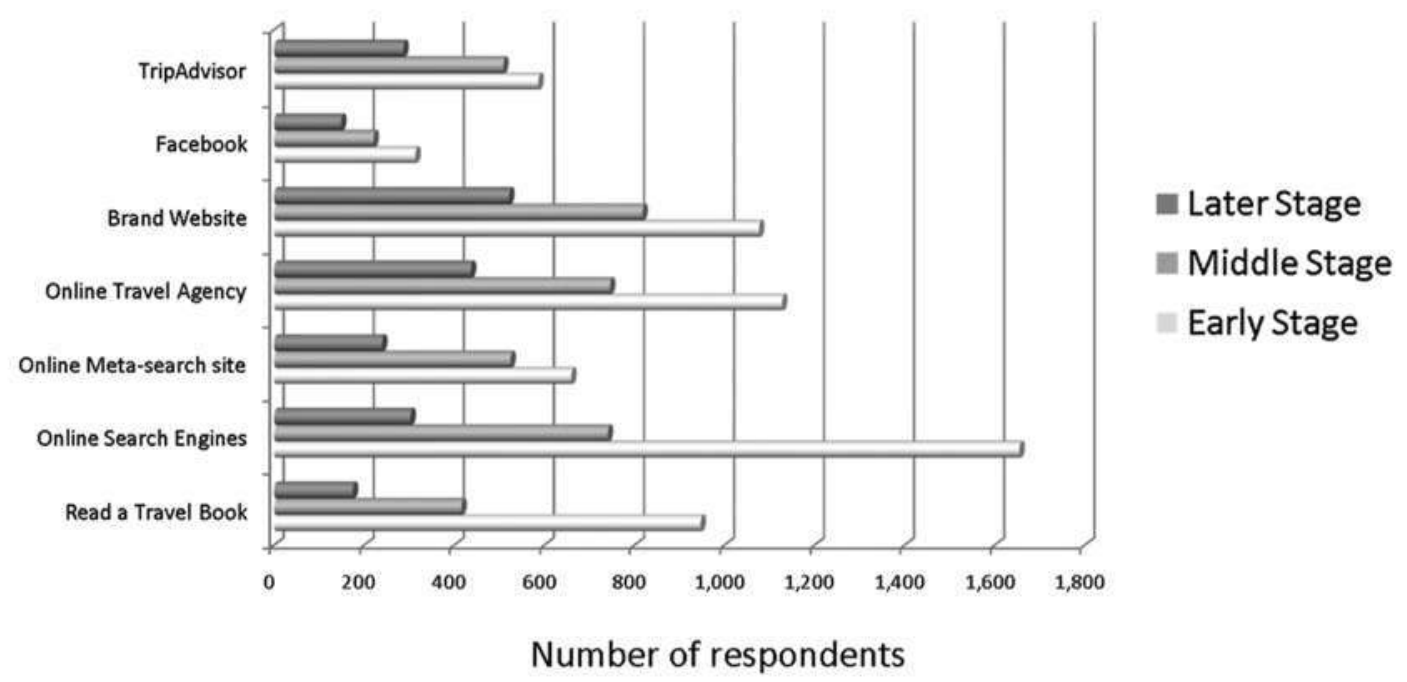

friends and family, which was cited by half male respondents and nearly 60 percent of women. Search engines (Google, Yahoo, Bing), travel-related websites, and metasearch websites were also heavily consulted. As a follow-up, the respondents were asked to indicate which social media or customer review sites they consult when searching for information about hotels. The results show that women are significantly more likely to read a review on TripAdvisor compared to men. While women are equally likely to read both professional reviews (e.g., AAA) and customer reviews (e.g., TripAdvisor), men are more likely to use professional reviews.

\section{Information Search During Different Shopping Stages}

One thing we noticed is that consumers gravitate to different types websites at various stages of their purchase process. Many people begin by consulting an online search engine to see what is available in their intended destination (see Exhibit 1). However, after they've read the information on Google, Yahoo, or Bing (as likely examples), many indicated that they visit brand websites, online travel agencies (e.g., Expedia, Travelocity), and read travel books to triangulate information on prospective hotels. Once the decision set is created, online search engines are no longer the dominant medium for information. At this point, customers are equally likely to visit hotel brand websites, online travel agencies, and online search engines. It is during this stage that customer reviews posted at TripAdvisor and meta-search sites seem to come most strongly into play. When it comes time to book, respondents preferred hotel brand websites and online travel agencies, although they also used other sites.

\section{The Impact of Customer Reviews}

The hotel industry is well aware that customer ratings have a strong effect on customers' willingness to book a hotel. We sought to quantify that effect by asking our respondents to rate their likelihood of choosing a hotel if they see a negative or a positive comment about the hotel that they are considering. When a hotel has negative comments, we found that the respondents gave a probability of about 2 out of 5 that they'd book that hotel. When they see a positive review, they estimated a likelihood of 3.5 to 4 out of 5 that they'd book that hotel.

\section{Customer Preferences for Mobile Apps}

Finally, we wanted to investigate which mobile device innovations our respondents would most like to see. On balance, location-based information and applications are most desired, followed by communication-based innovations and hotel-services-based innovations (see Exhibit 2). This was equally true for business and leisure customers. Location-based innovations include information about, directions to, and the ability to make reservations at local restaurants and other attractions. Communicationsbased innovations include text-messages or alerts from hotels, voice-mails, emails, and wake-up calls; and hotel services include the ability to use a mobile device to order 


\section{Exhibit 2:}

Relative Preferences for Mobile Innovations (5 = most preferred)

\section{All smart phone users (business smart-phone users)}

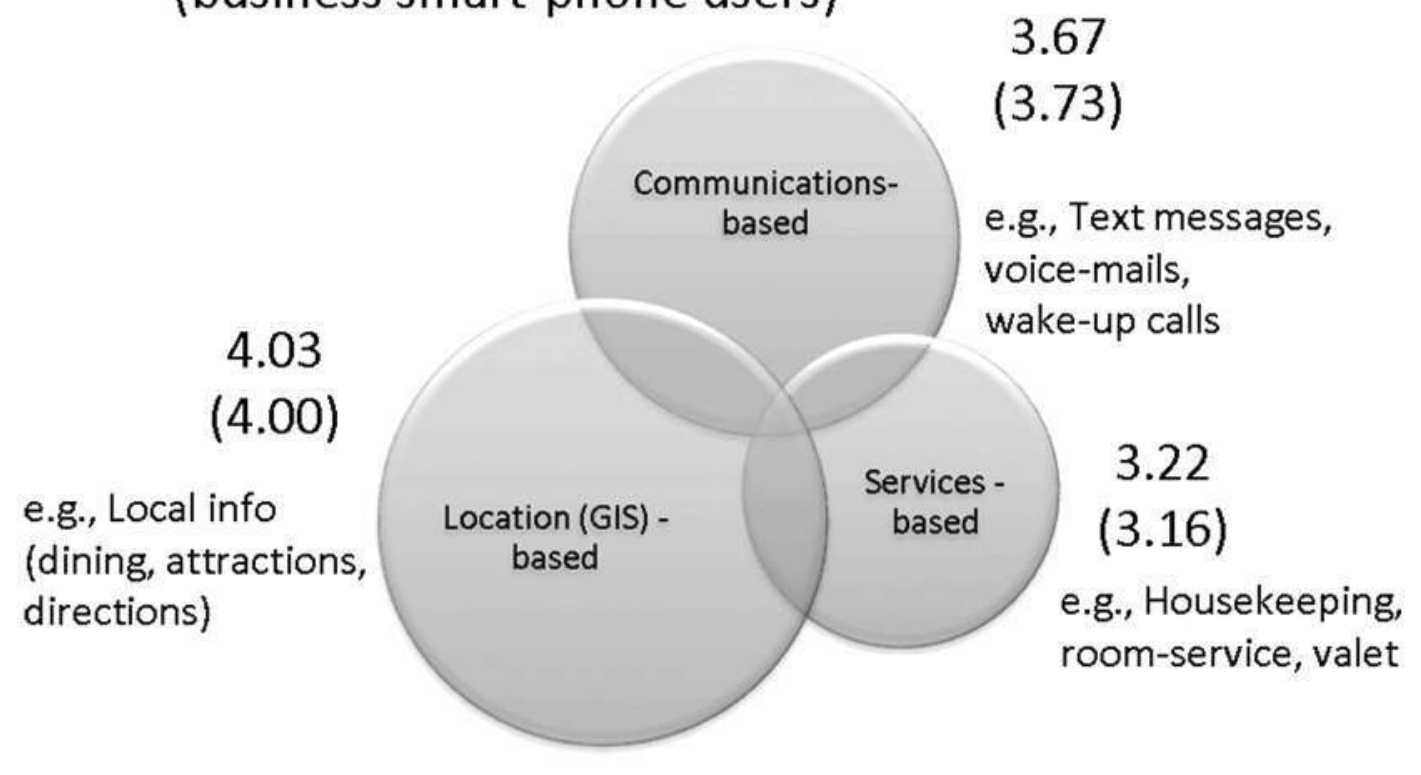

or schedule housekeeping, room-service, or other hotel services.

To get a sense of who uses mobile devices, we tested the technology readiness of each respondent, using the Technology Readiness Index (TRI, as developed by Parasuraman and Colby 2001). We found that individuals with higher TRI scores (who are thus likely to adopt technology) are slightly younger, travel more frequently on business, are more educated, and earn higher wages. Any gender differences that might have existed in the past have disappeared. We conclude that business users are more likely to adopt new technology at a faster rate than the rest of the population.

\section{Staying in Touch with Guests' Preferences}

As you have no doubt concluded on your own, because of the rapidly changing landscape of online information sources, there are no easy answers regarding guests' preferences and use of technology. One finding that's worth repeating is the way that individuals use different sources of information during the early, middle, and later stages of their purchase process. Also worth underscoring is the universal nature of technology use. Many commonly believed differences (e.g., due to gender, demographics, or hotel category) are no longer significant for many information search categories. Finally, your guests will be appreciative if you make it possible for them to enjoy your town and hotel by offering them location-based information and services for their mobile devices. Beyond that, we know that technology use is still a work in progress, and any conclusion written today will seem quaint in the near future.

\section{Declaration of Conflicting Interests}

The author(s) declared no potential conflicts of interest with respect to the research, authorship, and/or publication of this article.

\section{Funding}

The author(s) received no financial support for the research, authorship, and/or publication of this article.

\section{References}

Bodenlos, Greg, Victor Bogert, Dan Gordon, Carter Hearne, and Chris Anderson. 2010. Best practices in search engine marketing and optimization: The case of the St. James Hotel. Cornell Hospitality Reports. Vol. 10, No. 16. Cornell Center for Hospitality Research.

McCarthy, Laura, Debra Stock, and Rohit Verma. 2010. How travelers use online and social media channels to make hotel-choice decisions. Cornell Hospitality Reports. Vol. 10, No. 18. Cornell Center for Hospitality Research. 
Parasuraman, A., and C. L. Colby. 2001. Techno-ready Marketing: How and Why Your Customers Adopt Technology. New York: Free Press.

Verma, Rohit, Liana Victorino, Kate Kamiouchina, and Julie Feickert. 2007. Segmenting hotel customers based on the technology readiness index. Comell Hospitality Reports. Vol. 7, No. 13. Cornell Center for Hospitality Research

Verma, Rohit, and Russell Atthur Smith. 2010. The quest for consistent ratings. Cornell Hospitality Roundtable Proceedings. Vol. 2, No. 2. Comell Center for Hospitality Research.

\section{Bios}

Rolit Verma, Ph.D., is professor of service operations management at the Conell University School of Hotel Administration, and executive director of the Comell Center for Hospitality Research (rv54@comell.edu).

Debra Stock and Laura McCartlyy are graduates of the School of Hotel Administration and completed the research discussed here as students. 